\title{
Analyzing Factors That Can Attract Outsourcing Production to Tanzania
}

\author{
David Edward Mwambene, Japhet Jacksoni Katanga \\ School of Economics and Business Management, Zhejiang Normal University, 688 Yingbin Avenue, Jinhua \\ City, Zhejiang Province, 321004, P.R. China
}

\begin{abstract}
In recent year there is huge changes in value creation mode for most of conglomerate companies, there is no more labor intensive production process but high capital and digital tech-oriented. Labor cost is very high in developed country where most of this companies are located, so most of them tend to shift to underdeveloped and developing countries like Tanzania where though they have other challenges like low technology, insufficient infrastructure but they tend to offer low cost on labor cost as compared to developed countries. The paper was intend to find supporting evidences on what exactly factors would influences companies to outsource production to Tanzania. The results was Tanzania as any developing country has bright future on skilled, semi-skilled and unskilled labor, promising infrastructure development, low cost of production, access to new market, favorable government policies and abundantly raw material for production.
\end{abstract}

Keywords: outsourcing, production, Tanzania

DOI: $10.7176 / \mathrm{JESD} / 10-4-09$

\subsection{INTRODUCTION}

Outsourcing refers to strategic process when a certain company hand over the completion of certain tasks to another company or individual not employed by the company directly. Mcmillan (2010) Outsourcing refers to the transfer of a business activity or function from a client/customer to a local or foreign third party service provider (LLP, 2010). This outsourced individual or company can be domestic or oversees. Domestic outsourcing refers to outsourcing where both the primary company and the independent contractor or subsidiary are located in the same country.

Overseas Outsourcing its associated with giant companies which based on long term strategic advantages, they tend to use for developing countries as an opportunities for them to enjoyed a super normal profit and ensure sustainability development of their companies in future i.e.. Adidas, Toyota, Nike however even some smaller companies, employ manufacturing plants overseas in third world countries to upsize their profits. This is significant because their costs including wages, materials and building lease would be considerably higher in developed countries than they are in these other countries.

\subsection{OBJECTIVES}

To examine what factors can add value to the company who seek outsourcing opportunity in Tanzania. To examine how much those factors contribute to add value to a company.

\subsection{REASONS BEHIND OUTSOURCING}

Control costs. Outsourcing help company in cutting cost either fixed or variable cost. Example labor cost in developing country is lower compared to developed country, this could be due to strong union protections which unite workers compared to developing workers who normally seek for survival, according to (Borren, 2014) the average hourly wage rate in Chinese manufacturing workers is less than tenth that of their average U.S. Outsourcing allows organization to provide service at lower cost structure, which resulted from economies of scale (UKessays, 2017).

Increase efficiency. Using company resources to do everything on product development process will lead to company miss a competitive advantages of economies of scale from outsourced company, research cost, development, marketing, and distribution expenses, all of which must be passed on to customers. An outside provider's cost structure and economy of scale can give your firm an important competitive advantage.

Start new projects quickly. A good outsourcing firm has the resources to start a project right away. Handling the same project in-house might involve taking weeks or months to hire the right people, train them, and provide the support they need. And if a project requires major capital investments (such as building a series of distribution centers), the startup process can be even more difficult.

Focus on your core business. Every business has limited resources, and every manager has limited time and attention. Outsourcing your business processes would free your energies and enable you to focus on building your brand, invest in research and development and move on to providing higher value added services. According to (Borren, 2014) outsourcing has sense that it allows you to focus on what you do best'.

Reduce risk. Outsourcing providers (company), have full aware about the situation of the Markets, competition, 
government regulations, financial conditions, and technologies as that they all change very quickly. Outsourcing company will manage this risk for you, and they generally are much better at deciding how to avoid risk in their areas of expertise.

\section{LITERATURE REVIEW}

\subsection{BACK GROUND}

Currently business environment is really challenging, companies are striving to find and develop the best strategies to achieve efficiency and leverage their capabilities. One viable solution for them is outsourcing, which currently is considered to be one of the best ways of reshaping management. Chase defines Outsourcing as the act of moving some of a firm's internal activities and decision responsibility to outside providers. (Chase, 2011)

According to chase (Chase, 2011) Outsourcing goes beyond the more common purchasing and consulting contracts because not only are the activities transferred, but resources that make the activities occur, including people, facilities, equipment, technology and other assets are also transferred as well.

Business strategic thinking has been changing radically from the early 60's due to the need of new systematic approach of management and market strategies approach. Business now days consider customer loyalty, customer service and significant quality as the main focus on doing business which is different from early production quantity approach.

\subsection{OUTSOURCING THEORIES:}

Outsourcing is the strategic decision which has complex structure, it includes a lot of risk assessment in different activities that obviously requires many managerial decision making. Literature cover numerous benefits associated with outsourcing, such as cost reduction, focus on core competencies, access to suppliers with economies of scale and specialized process knowledge, and the ability to leverage existing capital investments and expensive technology (Asmussen, 2018). All of this reasons has attracted many scholars to develop different theories to help understand the nature and theoretical approaches of those activities and help successfully management of the process.

\subsubsection{Transaction cost economies}

The theory provides the basic decision making tools to help organization to decide to outsource and to prepare themselves forthcoming outsourcing arrangements. Total cost economies theory is the most utilized theory, guiding the bases of outsourcing, from starting stage up to contractual complexity of contract. The governance features of the theory influenced that it has been applied in studying the Managing relationship phase, whilst the concept of switching costs made the theory applicable in the reconsideration phase (Pedersen, 2007).

\subsubsection{Relational View}

The concept behind rational view theory is basis to explain how firms chooses their outsourcing partners and preferred type of relationship (Pedersen, 2007).Relational view develops and explains how firms gain and sustain competitive advantage within inter-organizational relationships (McIvor R., 2005). The theory has been used in explaining transition process, reconsideration phases and managing relationship.

\subsubsection{Concept of Core Competences}

The theory provides the basis to understand and select which is core competence of the firm existence and what are the strategic activities that firm can outsource. The concept has been predominantly use to develop and test various outsourcing decision frameworks arguing that the core activities shall remain in house (Pedersen, 2007).

\subsubsection{Resource-based View}

Global resources are scarcity, considering this resource based view explains that resources tend to vary significantly across different firms. According to (Pedersen, 2007) outsourcing builds from a proposition that an organization that lacks valuable, rare, inimitable and organized resources and capabilities, shall seek for an external provider in order to overcome that weakness.

\subsection{OUTSOURCING PRODUCTION}

Value creation process in recent years has been changing due to economic, social, environment and political factors. Many digitalized and globalized companies from developed country they no longer focus on improving the efficiency of their own production plants, outsourcing has emerged as alternative strategy. "Production outsourcing is the act of allocating production, previously performed by the organization, or under contract in the home country, to a third party or a wholly-owned subsidiary in a foreign country (Arnel, 2006)'”. Outsourced manufacturing, interchangeably referred to as "Collaborative" or "Contract" manufacturing or "Subcontracting" in some industries, is rapidly emerging as a practice adopted by most industries (Oracle, 2014).

Mary argue that outsourcing production activities to external sources had a significant effect on how manufacturing firms develop, produce, and deliver products to their customers (J., 2014). Outsourcing for the manufacturing process is directly related to the value-added transformation of raw materials and components into finished products, and non-core processes as all other activities. Recently number of outsourcing ventures has 
soared where large and small firms are relocating or outsourcing production to cost-effective locations as never before.

However the study by (Hagerty, 2012) find out that despite the importance of an effective outsourcing strategy, plants have not consistently experienced improvement in financial performance when outsourcing some portion of their operation. That tend to be among major factor for the recently campaign of bringing jobs back to the plants in the USA, due to both disappointment in the outcome of the original outsourcing decision as well as a changing global cost structure (Asmussen, 2018). Moreover; outsourcing remains a principal mechanism for improving manufacturing supply chains

\subsubsection{MOTIVATION OF OUTSOURCING PRODUCTION}

In a manufacturing firm, production is the single most costly part in a firm, often constituting up to $60 \%$ of total costs, whereas some sources even put the figure as high as $80 \%$ depending on industry (Dubois and Pedersen, 2001). This justifies that, any cost-cutting in production will significantly raise the profit margin in any manufacturing firm and thus increase firm value.

Outsourcing to emerging and developing countries like Tanzania which are has low-wage rate, help most in radical cost-cutters. According to Fredrik and Sall (Arnel, 2006) 'Outsourcing in tradition view was focused on cost reduction, organizational restructuring and focus on core competence but currently outsourcing is much more strategic decision for the future growth of the company'. However the business environment on recent days has changed to the extent that companies must evaluate the whole outsourcing process i.e.. Competency of asset transfer, the benefits and risk but also economy of scare utilization to outsourced destination this describes business strategic decision.

\subsection{TANZANIA AS AN OUTSOURCING DESTINATION}

Tanzania is a developing country with promising future potential in different aspect, politically, socially and economically. Politically Tanzania under President Magufuli its experiencing industrialization economy reform which has many opportunity for foreigner investors and local investors. Tanzania investment center (TIC) is an organ responsible to promote investment in Tanzania. TIC has put forward some strategic area that investors in Tanzania can consider (TIC, 2015), project which “"

$\checkmark$ Contribute higher on creating more employment opportunities,

$\checkmark$ New and innovative technology to be introduced by the Prospective investors strategic project,

$\checkmark$ The sustainable project effect on manufacturing exportation product to raise foreign currency and

$\checkmark \quad$ Investing in Special Economic Zone or Geographically disadvantaged regions.

Industrialization economy reform has made some changes in economic policies to attract and support investment on different sectors, factors that can attract companies to outsource in Tanzania includes:

Availability of skilled, semi-skilled and unskilled labor with lower salary base this will motivate international companies to invest in Tanzania. Tanzania has a total population of about 59 million (according to recently data by UN) with growth rate of $5.7 \%$, ranks as number 24 in the world list, the population density is 67 per kilometer square while $32.6 \%$ of this population live in urban centers. More than $65 \%$ of Tanzania population is youth having age less than 25 years old, this means youth counts a large number of Tanzania population.

Potential geographical location, Tanzania has boarded with six land locked country which are; Rwanda, Burundi, Uganda, Malawi, Zambia and DRC Congo all of ensure potential market segment due to high connection in terms of roads and rail networks.

Rich resources land, Tanzania she is blessed with range of different resources which can be raw material for many manufacturing industry. Currently Tanzania has possibility to have enough power supply from either gas or uranium as a source of efficient electric to support industry activities-this was one of biggest challenge for heavy duty industry to settle in Tanzania.

However regardless of this potential promising factors to support outsourcing in Tanzania-there are still challenges that investors must be aware off about Tanzania, high tax base set which discourage and read to high price of final product which automatically affect final consumption of product, possibility to experience high cost on production due to low level of technology lastly these investors must be aware of government bureaucracies and intervention on business operation.

\subsection{METHODOLOGY}

This article use surveys to collect information about benefit and risk of outsourcing production to Tanzania investment. Survey was done utilizing advantages of internet literature on outsourcing and identifies strategic drivers and options that can help Tanzania benefit from outsourcing as strategy to strengthen investment condition in the country. To understand why nations can gain competitive advantage through outsourcing and how companies can benefit from outsourcing in Tanzanian we create five factor to assess the effect on investment namely raw material, cost, labor, new market and government policy. The paper discusses Tanzania current policy under 
industrlization for sustainable economy.

\subsection{Conceptual framework}

This displays on input and output, whereby output indicate as dependent variable and input replace independent variables. For any changes which brought input on the way of outsourcing process will definitely have an impact to outputs. The independent variables of the study are Raw material, cost, labor, new market and government policy.

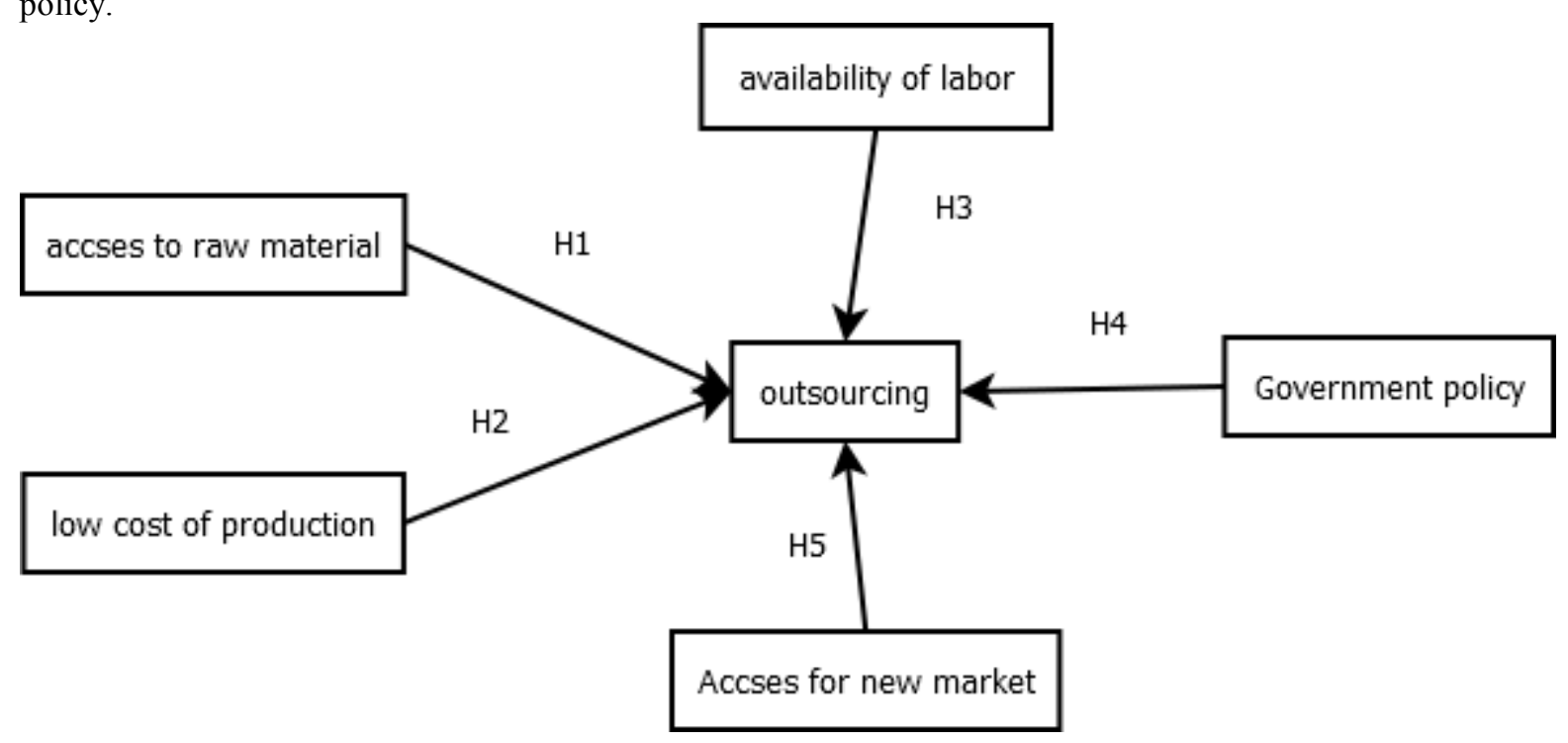

Figure 1: Source of information :( paper 2019)

\subsubsection{Hypothesis developed}

$H_{1}$ Raw material has impact on attracting outsourcing to Tanzania

$\mathrm{H}_{2}$ : Low cost has impact on attracting outsourcing to Tanzania

$H_{3}$ : Availability of Labor has impact on attracting outsourcing to Tanzania

$\mathrm{H}_{4}$ : Government policy has impact on attracting outsourcing to Tanzania

$\mathrm{H}_{5}$ : Accesses to new market has impact on attracting outsourcing to Tanzania

\subsection{Population and sample}

To collect data we needed to choose a population and determine a sample to be used in the research. According to Churchill (2005), population is defined not only as people, but also to manufacture and retail firms, organizations, marketers, countries or even inanimate objects. Target population instead, is defined as the totality of cases that conform to some designated specifications. The specifications define the elements that belong to the target group and those that are excluded. Churchill defines sample as a "selection of a subset of elements from a larger group of objects" and in sample survey it is meant to represent the target population (Churchill, 2005, p. 322).

In order to obtain the information we conducted an offline questionnaire during the month of October 2018. Questionnaires were distribute randomly to university students from different universities in Tanzania especially Dar es salaam and finally, there were obtained 255 valid responses. The questions, based on a five-point likert scale Questionnaires with a score less than 5.0 on any of the four items were eliminated.

\subsection{DATA FINDING AND DISCUSSION}

\subsection{Reliability and Validity Measurement}

Table 1 Reliability test

\begin{tabular}{lcc}
\hline Cronbach's Alpha Cronbach's Alpha Based on Standardized Items & $\mathrm{N}$ of Items \\
\hline .812 & .812 & 6 \\
\hline
\end{tabular}

According to Cronbach's Alpha a better commonly test based on the rank of $1.0<\mathrm{A}>0.5$ which indicate that, the excellent Alpha should less be than 1 and greater than 0.5, Cronbach's Alpha for the projects is 0.812 which value the $80 \%$ of the variable for 6 items will indicate the accurate internal score for the consistence reliable of the variance. 


\subsection{Correlation Analysis}

Table 2 correlation

\begin{tabular}{lllllll}
\hline & IN & RM & C & NM & GP & LB \\
\hline IN & 1 & & & & & \\
RM & 0.584 & & & & & \\
LC & 0.423 & 0.365 & 1 & 1 & & \\
NM & 0.864 & 0.285 & 0.337 & 0.457 & 1 & \\
GP & 0.321 & 0.375 & 0.253 & 0.381 & 0.421 & 1 \\
LB & 0.310 & 0.234 & 0.421 & & &
\end{tabular}

Correlation is significant at the 0.01 level (2-tailed).

Refer to the Table of correlation above shown all the variables are strong positive each other but regard on $\mathbf{p}$ significant should be less than $0.001(p<0.01)$, based on $p$ significant $(p<0.01)$ the relationship between access to new market doesn't pass the significant level, but other variable shown $p$ significant $(p=0.000)$, which means there are true actual capability of finding correlation between this variables and outsourcing production in Tanzania.

\subsection{Regression Coefficients analysis}

The relationship between independent and dependent variable via regression coefficient analysis can be describe as; $\mathbf{Y}$ is Outsourcing production, where by $\mathbf{Y}=$ dependent variable

Table 3 Model Summary

\begin{tabular}{ccccc}
\hline Model & R & R-Square & Adjusted R square & Std.Error Estimation \\
\hline 1 & 0.621 & 0.486 & 0.236 & 0.69766 \\
\hline
\end{tabular}

\section{ANOVA ${ }^{\mathrm{a}}$}

Table 4 Anova

\begin{tabular}{llllll}
\hline Model & Sum of squares & D.f & Mean square & F & sig. \\
\hline Regression & 120.862 & 5 & 30.216 & 63.079 & .000 \\
Residual & 192.256 & 395 & 0.487 & & \\
Total & 313.118 & 399 & & & \\
\hline
\end{tabular}

According to ANOVA "Analysis of variance" the model indicate F-ratio was $(\mathrm{F}=63.079$ and $\mathrm{p}=.000)$ there are statistically significant.

Table 5 Coefficient Table

\begin{tabular}{|c|c|c|c|c|c|}
\hline Model & $\begin{array}{l}\text { Unstandardized } \\
\text { Coeffnt B }\end{array}$ & Std.Error & $\begin{array}{c}\text { Standard } \\
\text { Coeffnt B }\end{array}$ & $\mathbf{T}$ & Sig. \\
\hline Constant & 1.696 & 0.163 & & 7.715 & 0.000 \\
\hline $\mathrm{RM}$ & 0.222 & 0.081 & 0.220 & 2.737 & 0.005 \\
\hline $\mathrm{LC}$ & 0.036 & 0.079 & 0.035 & 0.453 & 0.006 \\
\hline NM & 0.211 & 0.081 & 0.206 & 0.211 & 0.064 \\
\hline GP & 0.345 & 0.765 & 0.345 & 0.421 & 0.012 \\
\hline $\mathrm{AB}$ & 0.231 & 0.654 & 0.432 & 0.231 & 0.004 \\
\hline
\end{tabular}

The regression coefficient analysis equation is, $Y=\mathbf{a}+\mathbf{X 1}+\boldsymbol{\beta 1 X 2}+\boldsymbol{\beta 2 X 3}+\boldsymbol{\beta 3 X} \mathbf{X}+\boldsymbol{\beta} 4 \mathrm{X5}+\boldsymbol{\beta 5 X 6}$, whereby

$\beta 1, \beta 2, \beta 3, \beta 4, \beta 5$ - coefficient for five variables. While $\mathrm{X} 1$ raw material, $\mathrm{X} 2$ low cost of production, $\mathrm{X} 3$ new market, X4 government policy and X5 availability of labor independent variables of our research model.

Table below it's shown the outcome after test different Hypothesis through regression coefficient analysis, Table 3 represents multivariate regression analysis to measure the combined effect of independent and dependent variables. The result indicated that out of five proposed factors to attract outsourcing factors to Tanzania, only Access to new market is not significant related to factors that can attract outsourcing to Tanzania with $P$ value $\mathrm{p}<0.05$ ). All of the four proposed hypothesis were accepted as factors influencing outsourcing to Tanzania.

Table 6 hypothesis results test

\begin{tabular}{lcc}
\hline Model & Significance & Decision \\
\hline Accesses to raw material $\left(\mathbf{h}_{\mathbf{1}}\right)$ & 0.005 & Supported \\
Low cost $\left(\mathbf{h}_{\mathbf{2}}\right)$ & 0.006 & Supported \\
Availability of Labor $\left(\mathbf{h}_{\mathbf{3}}\right)$ & 0.004 & Supported \\
Government policy $\left(\mathbf{h}_{\mathbf{4}}\right)$ & 0.012 & Supported \\
New market $\left(\mathbf{h}_{\mathbf{5}}\right)$ & 0.064 & Not-supported \\
\hline
\end{tabular}

The table 4 shows accepted proposed research hypotheses, where H1: access to raw material has impact on attracting outsourcing to Tanzania. Also hypothesis H2: Low cost has impact on attracting outsourcing to Tanzania was accepted, $\mathbf{H 3}$ availability of labor has impact on attracting outsourcing to Tanzania was accepted and lastly regarding the hypotheses $\mathbf{H 4}$ Government policy has impact on attracting outsourcing to Tanzania was accepted too. As for the $\mathbf{H 5}$ access to new market has impact on attracting outsourcing to Tanzania has proven to have no 
influence on attracting outsourcing investment to Tanzania.

\subsection{Implications of the Research Findings}

The purpose of this research paper was to examine what factors can help to attract investors to consider outsourcing production to Tanzania and five factors were developed to try to test how much they can be source of boosting Tanzania investment through outsourcing strategy name: Access to raw material, Low cost, Availability of labor, attracting government policy and lastly access to new market. Five hypotheses were developed to test the relationships between proposed factors on attracting outsourcing in Tanzania.

The paper final findings will directly help to give information to new investors who are seeking for new opportunity in Africa exactly in Tanzania. These findings will also help government of Tanzania to use the proven factors to make sure they use them to attract new investors by explaining the potential benefit that they will have if the invest in Tanzania.

Advantages in costs control, company will be able to enjoy cost control by cutting variables based on company in cutting cost on labor cost where average salary for workforce in Tanzania 365,000 TZ shillings which is lower compared to developed country. Tanzania has advantages to create its neighborhood strong market since it has surrounded by six countries which trade with Tanzania on different products, investing in having factory in Tanzania will help to reach this customers easily and cut unnecessary transportation and handling cost, moreover this was not proven from the study since hypothesis for new market was denied.

However Tanzania is now experiencing growth in both skilled, semi-skilled and unskilled labor force (according to recently data by UN) Tanzania has 59 million people, with growth rate of 5.7\%, ranks as number 24 in the world list. More than $65 \%$ of Tanzania population is youth having age less than 25 years old. Youth age of Tanzania is one of valuable resources for the sustainable development of country, they represent a group that attend different levels of school, source of labor for different aspect into country economy generation.

Moreover Tanzania is full of natural resources to support production process, resources like natural gas, Coal, labor and many other different agricultural raw material like Cocoa, Cotton can both accommodate production for related final product in lowest possible cost and generate more profit for companies.

\subsection{Recommendation for farther study}

The sample size of this research was small, only 255 respondents was used to Justify the findings, Tanzania is big country with more than 59 million people, thus why we choose to target university students which probably they come into different parts of Tanzania and they represent the society of educated group they can help well to give reliable feedback for study. Further studies should be target investors, entrepreneurs and other business stakeholders with larger sample size than this study.

However it's recommended to future researches to expand the study to investigate more on what could be possible risks and other reasons that course conglomerate companies not to consider the whole Africa as opportunity like what happen in Asia for outsourcing their production

\subsection{Reference}

Arnel, F. (2006). Outsourcing Production to China: Risks and Benefits Based on Cases. School of Business

Ali Nazeri, D. o. (July 3 - 6, 2012). Outsourcing and Its Impact on Operational Performance. International comference on industril engeering and operations management instanbul, turkey at: http://toc.proceedings.com/21290webtoc.pdf

Borren, T. (2014. 5 Smart Reasons to Outsource Manufacturing Overseas. Gusto Payroll and Benefits.at: http://yfsmagazine.com/2014/02/15/5-smart-reasons-to-outsource-manufacturing-overseas/

Chase, F. J. (2011). Operations and Supply Chain Management, 13 edition. McGraw-Hill Companies, Inc \& China Machine Press.

Churchill Gilbert A., Iacobucci Dawn, 2005, Marketing Research: Methodological Foundations, Thomson/SouthWestern, p. 168, 212, 321, 322, 679

F. N. (June 2016). Effects of Outsourcing on Organization Performance Imanufacturing Sector in Kenya: a case of del monte kenya limited. European Journal of Logistics, Purchasing and Supply Chain Management, Vol.4, 32-58.

Hagerty, J.R. (2012), “Once Made in China: Jobs Trickle Back to US plants”, Wall Street Journal, May 23, available at: http://online.wsj.com/news/articles/SB100014240527023045877

J.M (2014). The Effects of Production Outsourcing on Factory Cost Performance. Journal of Manufacturing Technology Management.

Jesper N.Asmussen (2018) Outsourcing of Production: The Valuation of Volume Flexibility in Decision Making, Scientific journal of logistics

LLP, M. (2010). The benefits and risks of outsourcing, at: https://www.lexology.com/library/detail.aspx?g=e698d613- 
McIvor R. (2005). The Outsourcing Process, Cambridge. Cambridge, Strategies for Evaluation and Management. at: https://pdfs.semanticscholar.org/77d6/21e99e03de15ada9e13420acf125f0a0dfd0.pdf

Mcmillian Llp.(2010 April 6) The Benefits and Risks of Outsourcing. Sourced at: https:/www.lexology.com/library/detail.aspx?g=e698d613-af77-4e34-b84e-940e14e94ce4

Oracle (2014) Driving Outsourcing Manufacturing Best Practices with Oracle E-business suite Oracle white paper at: https://www.oracle.com/assets/outsourced-manufacturing-bp-2103699.pdf

Pedersen, Z. P. (2007). Outsourcing Process and Theories. Centre for Technology, Economics \& Management Denmark.

Stockholm University, Bachelor Thesis at: http://www.diva-portal.org/smash/get/diva2:196203/fulltext01

TIC. (2015). Why Invest in Tanzania. An overview of investments climate, opportunities, trends and services provided by Tanzania investment center.at: https://de.tzembassy.go.tz/uploads/Why_Invest_in_Tanzania.pdf

UKessays. (2017). Benefits of outsourcing to host country. At: https://www.ukessays.com/essays/commerce/benefits-of-outsourcing-to-host-country-commerce-essay.php 